\title{
FEATURES OF THE PHENOMENON OF RE- HOSPITALIZATIONS AND OPPORTUNITIES OF FORMATION OF ANTI-RELAPSE BEHAVIOR IN MENTAL DISORDERS
}

\author{
E. Gutkevich ${ }^{1,2}$, V. Lebedeva ${ }^{1}$ N. Bokhan ${ }^{1,2,3}$. S. Vladimirova ${ }^{1}$ \\ Academy of Sciences, Tomsk, Russia, mental@tnimc.ru. \\ ${ }^{2}$ National Research Tomsk State University, Tomsk, Russia \\ ${ }^{3}$ Siberian State Medical University, Tomsk, Russia
}

${ }^{1}$ Mental Health Research Institute, Tomsk National Research Medical Center, Russian

Objectives: Identification and justification of a set of clinicalsocio-demographic and pathopsychological factors that underlie a multi-level model of anti-relapse behavior. Background: The relevance is determined by the need to establish the factors of formation of anti-relapse behavior in mental disorders for heightening the quality of life of mentally ill persons. Materials and Methods: 180 patients were examined (59 men, 121 women) aged from 22 to 75 years with non-psychotic and schizophrenic mental disorders, with length of the disease from 1 year to 40 years, with number of repeated hospitalizations from 2 to 34 . Clinical-dynamic, questionnaire survey, experimental-psychological, clinical-genealogical, methods of mathematical statistics. 180 patients were examined using the developed "Questionnaire of anti-relapse behavior" with 10 questions which describe clinical-dynamic characteristics of disease, psychological characteristics of patient's personality, microenvironment (family) and macro-environment, social interactions, daily activities, resources of patient (see table). Results and Conclusions: In 2011-2015 re-hospitalization of patients with schizophrenic disorders was 50 persons a year $(10 \%)$. Clinical-genealogical investigation of families of probands revealed family history of mental diseases - schizophrenia, substance dependence, epilepsy. When re-hospitalized emotional tension, irritability, rigidity and formation of activity concepts for reduction of anxiety, instability of motives and domination of control over behavior within personality and vol

"Questionnaire of anti-relapse behavior"

\begin{tabular}{|c|c|}
\hline $\begin{array}{l}\text { No. of the } \\
\text { question }\end{array}$ & Content of the question \\
\hline $1-3$ & $\begin{array}{l}\text { Ideas of patients about their diagnosis and symptoms of } \\
\text { worsening their mental state }\end{array}$ \\
\hline 4 & $\begin{array}{l}\text { What positive and negative stresses were experienced by } \\
\text { patients }\end{array}$ \\
\hline 5-6 & Personality traits and communicative abilities \\
\hline 7 & Everyday functioning \\
\hline 8-9 & Some activities which should be avoided \\
\hline 10 & $\begin{array}{l}\text { Methods of reducing the risk of the exacerbation of the } \\
\text { disease }\end{array}$ \\
\hline
\end{tabular}

the attitude towards disease patients show rather adaptive or mixed variants. Patients with non-psychotic disorders in the actual state of relapses and repeated hospitalizations more often demonstrated anxiety, emotional instability, tension, with a low assessment of the meanings of the present, ease of fear about the state of their health, their future. In patients with schizophrenic disorders, irritability, rigidity, instability of motives and dominance of control over their behavior within the framework of personality and volitional characteristics were revealed. The most vulnerable areas of life for respondents with chronic mental illnesses and repeated hospitalizations were relationships with people around them. We have defined antirelapse behavior as the desired behavior of people with mental disorders using inpatient care, which stimulates the need to control symptoms, prevent recurrence of the disease (relapse) and repeated hospitalizations, by transforming internal resources and various external influences into manageable individual behavioral determinants in the system of cooperation of persons with mental disorders, their relatives, families and professionals in the field of mental health care. Interdisciplinary (psychiatry, psychology, genetics) study of the phenomenon of rehospitalizations of patients with mental diseases revealed factors that gave the chance for search of ways of decrease in number of re-hospitalizations within the rehabilitation clinical model "mental health - mental pathology" when treatment is minimization of disease, rehabilitation is maximization of health.

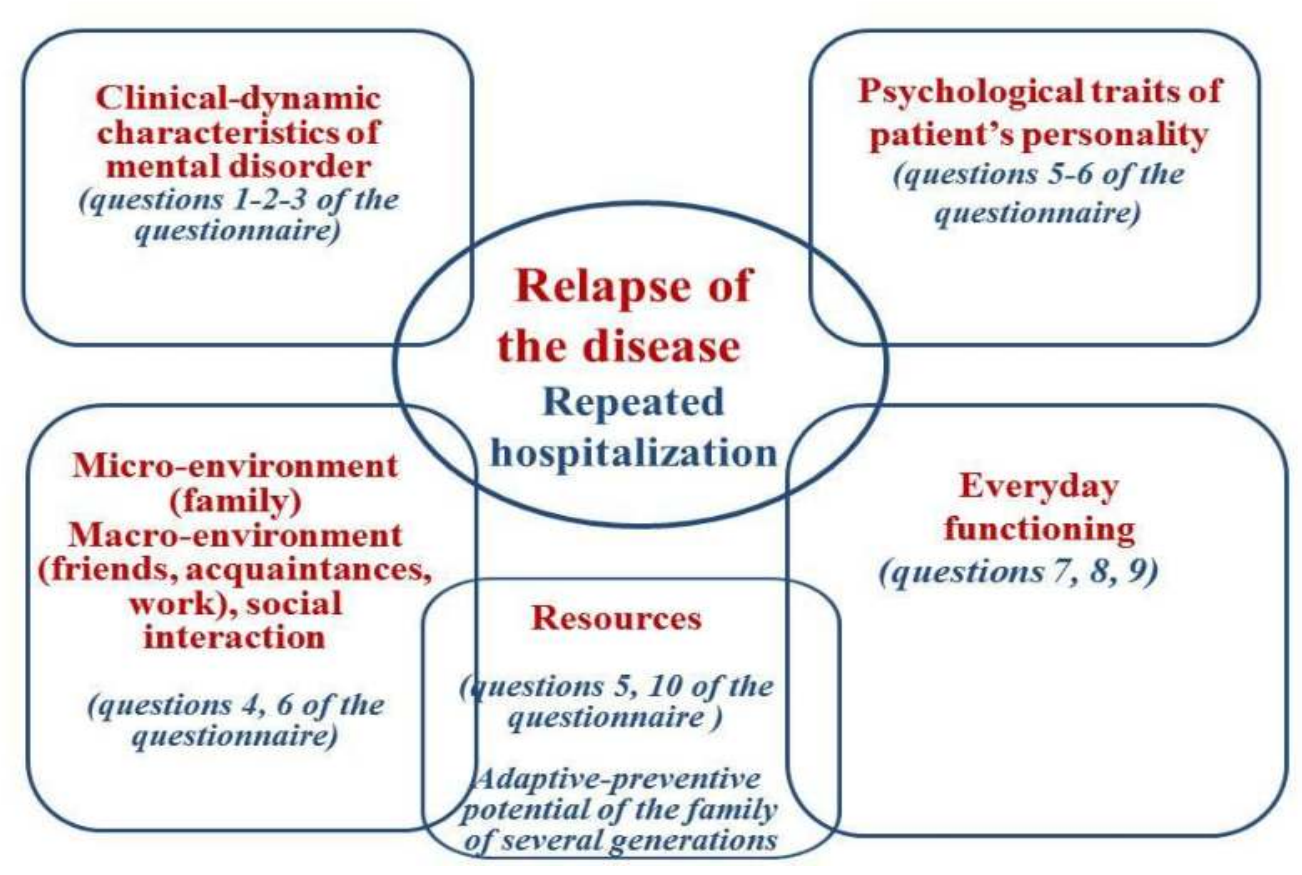

